\title{
Faecal progestagen profiles in wild southern white rhinoceros (Ceratotherium simum simum)
}

\author{
A.C. van der Goot ${ }^{1,2,7}$, F. Dalerum ${ }^{2,3}$, A. Ganswindt ${ }^{2,4^{\ddagger}}$, G.B. Martin', \\ R.P. Millar ${ }^{2,5,6,7}$ \& M.C.J. Paris ${ }^{1,2,7}$ \\ ${ }^{1}$ School of Animal Biology, University of Western Australia, Crawley, WA 6009, Australia \\ ${ }^{2}$ Mammal Research Institute, Department of Zoology and Entomology, University of Pretoria, \\ Pretoria, 0002 South Africa \\ ${ }^{3}$ Centre for Wildlife Management, Hatfield Experimental Farm, University of Pretoria, \\ Pretoria, 0028 South Africa \\ ${ }^{4}$ Department of Production Animal Studies, Faculty of Veterinary Science, University of Pretoria, \\ Onderstepoort, 0110 South Africa \\ ${ }^{5}$ UCT/MRC Receptor Biology Unit, University of Cape Town, South Africa \\ ${ }^{6}$ Centre for Integrative Physiology, University of Edinburgh, Scotland, U.K. \\ ${ }^{7}$ Institute for Breeding Rare and Endangered African Mammals (IBREAM), Edinburgh, \\ EH3 6AT, Scotland, U.K.
}

Received 4 December 2012. Accepted 20 April 2013

\begin{abstract}
Knowledge of the reproductive biology of wild animals can provide valuable information for the development of appropriate in situ and ex situ management plans. The present study aimed to establish a non-invasive protocol for monitoring faecal progestagen metabolite (FPM) patterns in wild female southern white rhinoceroses (Ceratotherium simum simum). Six adult females at Lapalala Wilderness, South Africa, were tracked and accurately identified at least once every week. Three animals gave birth during the study period. Fresh faecal samples were collected for 12 months and stored frozen at $-20^{\circ} \mathrm{C}$ until analysis with an enzyme immunoassay utilizing an antiserum raised against $5 \alpha$-pregnan-3 $\beta$-ol-20-one which cross-reacts with a number of progestagens. Mean FPM concentrations were 35 to 64 -fold higher during pregnancy (55-145 days before parturition) compared to postpartum (120-140 days after parturition) $(P<0.001)$. Also, the non-pregnant animals had mean FPM concentrations significantly higher than postpartum values $(P=0.006)$. Our results show that non-invasive FPM measurements provide information on the pregnancy status of wild female white rhinoceroses, and may be used for the detection of pregnancy in free-living individuals, without the necessity of immobilization and/or relocation of the animal. This information has potential value for optimizing breeding management of wild and captive populations.
\end{abstract}

Key words: progestagen, reproduction, wild populations, non-invasive, Ceratotherium simum.

\section{INTRODUCTION}

The African white rhinoceros (Ceratotherium simum), which was rescued from extinction at the end of the 19th century, is one of the five remaining species of rhinoceroses today. Together with the other surviving rhinoceros species, the African black (Diceros bicornis), Indian (Rhinoceros unicornis), Javan (Rhinoceros sondaicus) and Sumatran (Dicerorhinus sumatrensis) (Owen-Smith 1992) rhinoceroces, the white rhinoceros population faces an uncertain future. One of the major causes is the extremely high demand for its horn, which is being used as an ingredient in traditional

\footnotetext{
*Author for correspondence. E-mail: avandergoot@zoology.up.ac.za ${ }^{\ddagger}$ Present address: Department of Anatomy and Physiology, Faculty of Veterinary Science, University of Pretoria, Onderstepoort, 0110 South
} Africa.
Asian medicine and also in the manufacture of ceremonial curved daggers in the Middle East (Owen-Smith 1992; Emslie et al. 2009). Horn poaching involves killing the animal and removal of its horns. Due to the illegal hunting the black rhinoceros population, for example, has faced an overall population decline of $96 \%$ between 1970 and 1992 with a total number of 2162 animals left at that time (Emslie et al. 2009). The illegal hunting in South Africa is again steadily increasing from around 210 black and white rhinoceroses being poached in total between 2006 and 2009 to 333 in 2010, reaching 448 in 2011 (Milliken et al. 2009; Knight 2011). According to the latest 2012 census, by the South African Department of Environmental Affairs, 668 rhinoceroses have been illegally 
killed in 2012 (DEA, 06/03/2013) indicating a worsening situation. Rhinoceros horn has been valued for centuries by Asian traditional healers to cure a variety of ailments, such as snakebites, fever, headaches and food poisoning. However, one of the reasons described for the rapid increase in recent poaching accidents is the increase in demand for new use of rhinoceros horn in modern Asian therapies to treat diseases such as cancer, rheumatism and gout (Costa-Neto 2004; Milliken et al. 2009).Two genetically distinct subspecies of white rhinoceros exist, namely the northern white rhinoceros (Ceratotherium simum cottoni) and the southern white rhinoceros (Ceratotherium simum simum) (Owen-Smith 1992). Ground surveys in 2009 suggested that the northern white rhino was most likely eliminated from its range by civil war and poaching (Emslie et al. 2009), with only seven individuals remaining of this subspecies and in December 2009 four captive individuals were re-introduced from Dvur Kralove Zoo into OlPejeta Conservancy, into a secure reserve in Kenya, in an attempt to encourage natural breeding in the wild (Milliken et al. 2009). The southern white rhinoceros population is currently estimated to be 20920 (Emslie 2011), of which 93\% live in South Africa (Milliken et al. 2009). Although this number seems viable, rapid decimation of the population is possible, especially given the recent steady increase in poaching incidents (Ferreira 2012). Being classified as 'Near Threatened' on the IUCN's Red List of Threatened Species (Emslie 2011), the southern white rhinoceros population is dependent on effective protection and intensive conservation and management (Amin et al. 2003; Hermes et al. 2005). If the situation arose where the population became vulnerable again - as observed a century ago with only approximately 200 individuals remaining in the wild (Rookmaaker 2001) - successful breeding becomes an indispensable component of the overall conservation management strategies of the species.

Ex situ breeding can play a key role in maintaining rhinoceros populations today, with these captive populations serving as genetic stock and potential reservoirs for reintroduction into the wild. However, white rhinoceros females in captivity, especially from the captive-born (F1) generation onwards, show low reproductive success and aberrant cycling patterns. With a negative growth rate in captivity $(-3.5 \%$ as a percentage of the entire captive population), the sustainability of the captive population may be jeopardized (Roth
2006; Swaisgood et al. 2006; AZA 2009). A recent study found death rate to have been 1.19 times higher than birth rate for 2001-2004 (Ried et al. 2012). Currently, the captive white rhinoceros population is static $(\lambda-1.001)$ only because of the continuous importation of new individuals from the wild (Foose \& Wiese 2006; Emslie 2011). Thus, the current captive population is not self-sustainable. In contrast, observational studies suggest that wild white rhinoceroses do not show reproductive impairment (Swaisgood et al. 2006).

Our current understanding of the reproductive biology of the southern white rhinoceros is still limited. Literature reports the existence of two different oestrous cycle lengths in captive white rhinoceros, one with a luteal phase length of 30-35 days and the other of 65-70 days. Only the shorter cycle is believed to be fertile (Hindle et al. 1992; Schwarzenberger et al. 1993; Radcliffe et al. 1997; Patton et al. 1999; Brown et al. 2001). Also, periods of acyclicity have been found in captivity with a high incidence in both young and aged females (Brown et al. 2001; Hermes et al. 2006). These repeated non-fertile periods are potentially contributing to the development of a variety of reproductive pathologies (Hermes et al. 2006). The length of gestation in the white rhinoceros is estimated to be 16-17 months (Patton et al. 1999). Pregnancy can be diagnosed approximately 3-5 months postconception by elevated progesterone concentrations (Roth 2006). Only few observations have been made related to female reproduction in the wild (Owen-Smith 1992; Bertschinger 1994) and to date, no long-term reproductive hormone data are available from wild individuals.

Hormones are often measured in blood samples, and it is possible to condition captive individuals to collect routine blood samples without the use of anaesthesia (Steele 2002). In contrast, collecting regular blood samples from wild rhinoceroses is impractical, as the animal would need to be sedated, captured and intensively monitored by an anaesthetic team for each single blood sample, thus only opportunistic blood sample collections is justified when accompanying essential immobilization for other purposes. With the development of faecal hormone assays, it is possible to collect samples in a non-invasive way, and these methods have been used to study reproduction in captive rhinoceroses (Radcliffe et al. 1997; Schwarzenberger et al. 1998; Patton et al. 1999; Brown et al. 2001). Apart from the practical advantages, this technique also bypasses the potential negative 
Table 1. Background information on white rhinoceros individuals $(n=6)$ used in this study, including the estimated age of the accompanying (youngest) calf at the onset of the study in October 2008. The youngest calf of female 4 died a few hours after birth on 1 July 2006 for unknown reasons, therefore her older calf born on 4 November 2003 (i.e. female 6) was never chased away permanently. Female 6 was nulliparous at the onset of the study.

\begin{tabular}{llcll}
\hline Study animal & Date of birth (est.) & No. of calves & $\begin{array}{l}\text { Estimated age } \\
\text { youngest calf }\end{array}$ & $\begin{array}{l}\text { Mean interbirth } \\
\text { interval }\end{array}$ \\
\hline Female 1 & 1 Dec 1993 & 4 & 1 yr 7 months & 2 yrs 7 months \\
Female 2 & 1 Apr 1993 & 3 & 2 yrs 8 months & 2 yrs 11 months \\
Female 3 & 1 Jan 1993 & 3 & 1 yr 8 months & 2 yrs 5 months \\
Female 4 & 1 Feb 1996 & 2 & 4 yrs 11 months & 2 yrs 9 months \\
Female 5 & 1 Jan 1989 & 5 & 1 yr 2 months & 3 yrs 5 months \\
Female 6 & 4 Nov 2003 & 0 & - & - \\
\hline
\end{tabular}

effects of stress in the results when using invasive methods (Christensen et al. 2006; Wittemyer et al. 2007). Investigating reproductive hormone profiles will increase our knowledge of the reproductive physiology of wild female white rhinoceroses, and may contribute to understanding reproductive impairment in captivity.

The aim of the current study was to provide longitudinal data on faecal progestagen metabolite (FPM) concentrations in pregnant and nonpregnant wild individuals.

\section{MATERIALS \& METHODS}

\section{Animals and study area}

Fieldwork was conducted for a period of 25 months between October 2008 and October 2010 in the Lapalala Wilderness, a 36000 ha privately owned game reserve in the UNESCO Waterberg Biosphere Reserve in the Limpopo province, South Africa $\left(23^{\circ} 51 S, 28^{\circ} 16 \mathrm{E}\right)$. Lapalala Wilderness is situated in a summer rainfall area, with an annual rainfall ranging from 650 to $900 \mathrm{~mm}$ (Low \& Rebelo 1996). Average maximum summer and winter temperatures are $32^{\circ} \mathrm{C}$ and $22^{\circ} \mathrm{C}$, respectively, and average minimum temperature is $18^{\circ} \mathrm{C}$ in summer and $4^{\circ} \mathrm{C}$ in winter (Ben-Shahar 1987). The vegetation in Lapalala Wilderness belongs to the savanna biome and is classified as Waterberg moist mountain bushveld (Low \& Rebelo 1996).

Southern white as well as black rhinoceros have been successfully re-introduced into the reserve since the 1990s (Walker 1994). Based on information on previous reproductive success (Lapalala Wilderness, unpubl. data), six adult female southern white rhinoceroses were chosen as focal individuals for the study (Table 1). The date of birth of the focal individuals was estimated based on recorded ground observations by qualified rangers (Lapa- lala Wilderness, unpubl. data). Existing information on individual inter-birth intervals as well as the estimated age of the youngest calf (Table 1) was used for estimating the state of reproduction of the focal individuals.

\section{Faecal sample collection}

Regular faecal samples were collected from six wild adult female southern white rhinoceroses in a nature reserve in South Africa (Fig. 1). Three females gave birth during the course of this study. The six focal individuals were located through tracing their tracks. Each focal animal was observed at least at weekly intervals during the entire study period for faecal collection. Animals were identified using physical characteristics such as ear notches, horn size and scar tissue (Emslie \& Brooks 1999). Faecal samples were collected within $30 \mathrm{~min}$ after defecation. Approximately $50 \mathrm{~g}$ of homogenized faecal material was taken from the centre of a dropping and placed on ice immediately. All samples were frozen within two hours of collection and stored at $-20^{\circ} \mathrm{C}$ until analysis at the Endocrine Research Laboratory, University of Pretoria, South Africa.

\section{Sample processing and extraction}

Faecal samples were lyophilized, pulverized, and sifted using a metal mesh strainer to remove fibrous material (Fieß et al. 1999). Approximately $0.05 \mathrm{~g}$ of the faecal powder was then extracted with $80 \%$ ethanol in water $(3 \mathrm{ml}$ ) by vortexing for $15 \mathrm{~min}$ and subsequent centrifugation for $10 \mathrm{~min}$ at $1500 \mathrm{~g}$. Resulting supernatants were transferred into micro-centrifuge tubes and stored at $-20{ }^{\circ} \mathrm{C}$ until analysis.

\section{Assay procedures}

Faecal extracts were measured for immuno- 


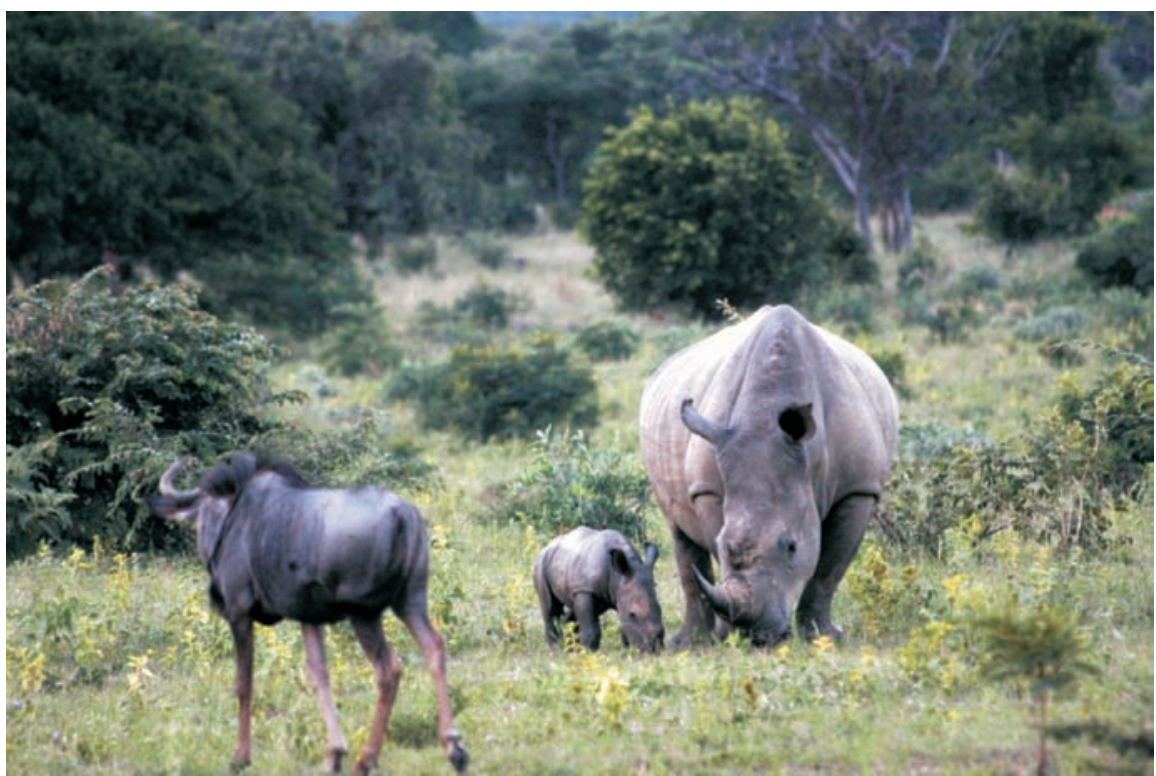

Fig. 1. Southern white rhinoceros female 2 (Fig. 2b) with a four-day-old newborn calf in Lapalala Wilderness, South Africa

reactive progesterone metabolites using an enzyme immunoassay (EIA) for $5 \alpha$-pregnan- $3 \beta$ ol-20-one, which has been shown to provide reliable information on reproductive steroid hormone pattern by reflecting total progestagens in different mammalian species (Szdzuy et al. 2006; Ahlers et al. 2012). The EIA used a polyclonal antibody against $5 \alpha$-pregnan- $3 \beta$-ol-20-one-3-hemisuccinate-BSA and $5 \alpha$-pregnan- $3 \beta$-ol-20-one-3hemisuccinate-peroxidase label (Szdzuy et al. 2006). Cross-reactivities of the antibody used are described by Szdzuy et al. (2006) and were as follows: $5 \alpha$-pregnan-3 $\alpha$-ol-20-one, $650 \%$; $5 \alpha$ pregnan-3 $\beta$-ol-20-one, $100 \%$; 4 -pregnen-3,20dione, $72 \%$; $5 \alpha$-pregnan-3,20-dione, $22 \%$; $<0,1 \%$ for $5 \beta$-pregnan-3 $\alpha, 20 \alpha$-diol, 4 -pregnen- $20 \alpha$ ol-3-one, $5 \beta$-pregnan-3 $\alpha$-ol-20-one, $5 \alpha$-pregnan$20 \alpha$-ol-3-one, $5 \alpha$-pregnan- $3 \beta, 20 \alpha$-diol and $5 \alpha$-pregnan-3 $\alpha, 20 \alpha$-diol. EIAs were performed following Prakash et al. (1987). Sensitivity (90\% binding) of the assay was $4 \mathrm{pg} /$ well. Intra- and interassay coefficients of variation, determined by repeated measurements of high and low value quality controls ranged between $9.3 \%$ and $16.5 \%$. To adjust for water content variations, FPM concentrations were expressed as mass/dry mass of faecal extract.

\section{Data analysis}

We allocated the faecal endocrine data into three different reproductive states: 1) pregnant (days 55-145 prior to parturition), 2) postpartum (days 120-140 following parturition), and 3) nonpregnant (cycling and/or anoestrus). We evaluated the effect of reproductive state on mean progestagen metabolite concentrations using a mixed model. This model contained the reproductive state as a fixed categorical predictor and sample date nested within each individual as a random effect structure. We fitted a variance power function to account for heteroscedasticidy. We evaluated the fixed effect by a conditional F-test (Pinheiro \& Bates 2000) and pairwise comparisons of reproductive states using Tukey contrasts. Statistical analyses were conducted using the package $R$ version 2.15.1 for Linux (http://www.r-project. org). We have reported data as individual means \pm 1 S.D.

\section{RESULTS}

There was a significant effect of reproductive state on progestagen metabolite concentrations $\left(F_{2,308}=\right.$ 49.54, $P<0.001)$, with mean FPMp concentrations during the pregnant phase being significantly higher than both the postpartum $(z=9.47, P<$ $0.001)$ and the non-pregnant $(z=9.51, P<0.001)$ phase. FPM concentrations in the non-pregnant phase were also significantly higher than the postpartum phase $(z=2.56, P=0.006)$. All three pregnant females showed a rapid decline in 

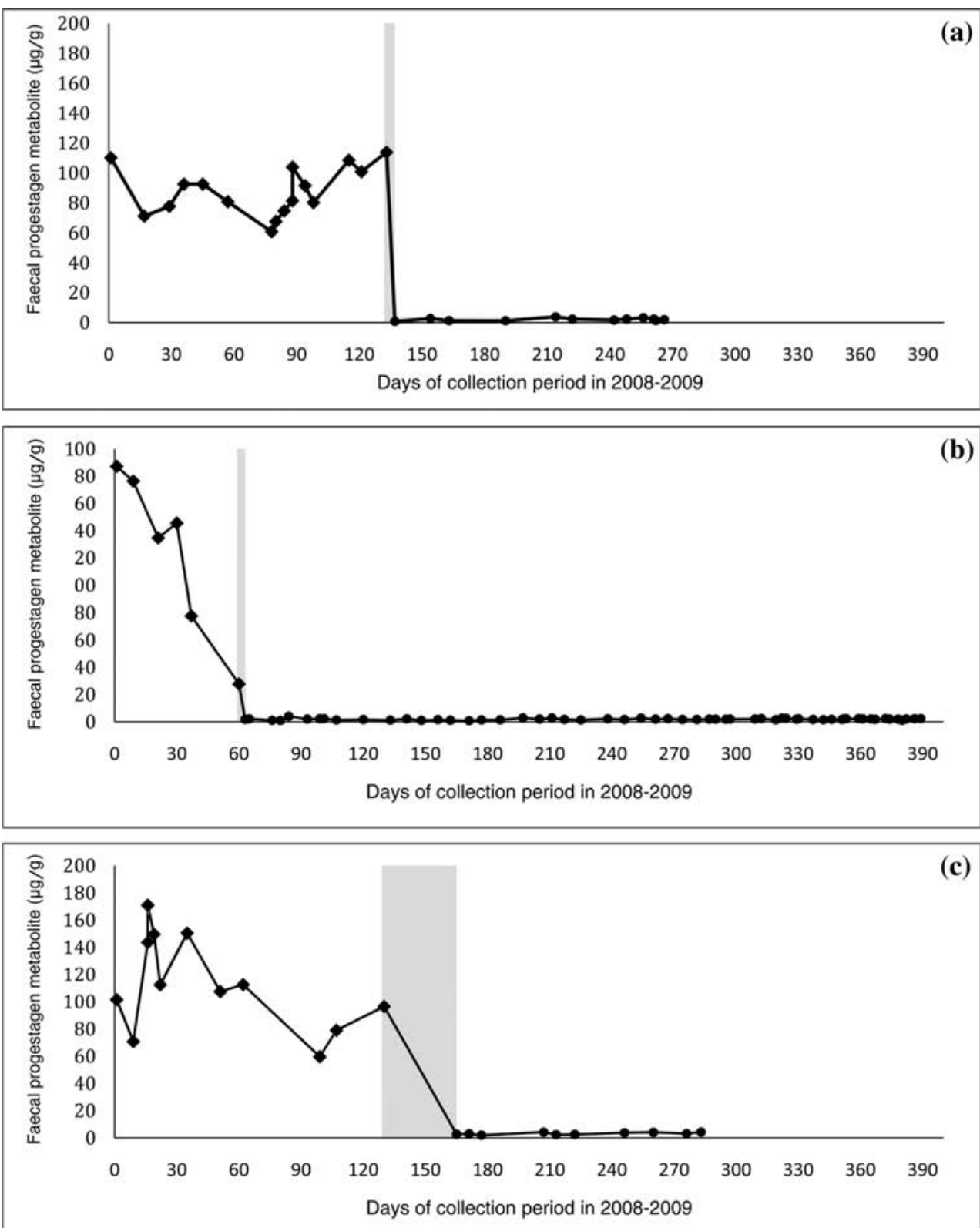

Fig. 2. Concentrations of faecal progestagen metabolite in wild southern white rhinoceros female 1 (a), female 2 (b) and female 3 (c) during late pregnancy $(\bullet)$ and postpartum $(\bullet)$ and in non-pregnant female 4 (d), female 5 (e) and female 6 (f). Moment of parturition (grey shading) was estimated based on the visual observation of a new calf. (Continued overleaf).

FPM concentrations around parturition and mean FPM concentrations prior to parturition were 35-64 fold higher $(124.87 \pm 61.16 \mu \mathrm{g} / \mathrm{g}$ faeces, $88.03 \pm 16.19 \mu \mathrm{g} / \mathrm{g}$ faeces, and $112.86 \pm 34.72 \mu \mathrm{g} / \mathrm{g}$ of faeces; Fig. 2a,b,c) than concentrations found postpartum $(3.09 \pm 6.02 \mu \mathrm{g} / \mathrm{g}$ faeces, $2.11 \pm 0.88$ $\mu \mathrm{g} / \mathrm{g}$ faeces, $3.20 \pm 0.83 \mu \mathrm{g} / \mathrm{g}$ faeces, respectively). Concentrations remained in this range for the following 120-140 days of postpartum sample collection in all three females.

Although mean progestagen metabolite concentrations for non-pregnant females were signifi- 

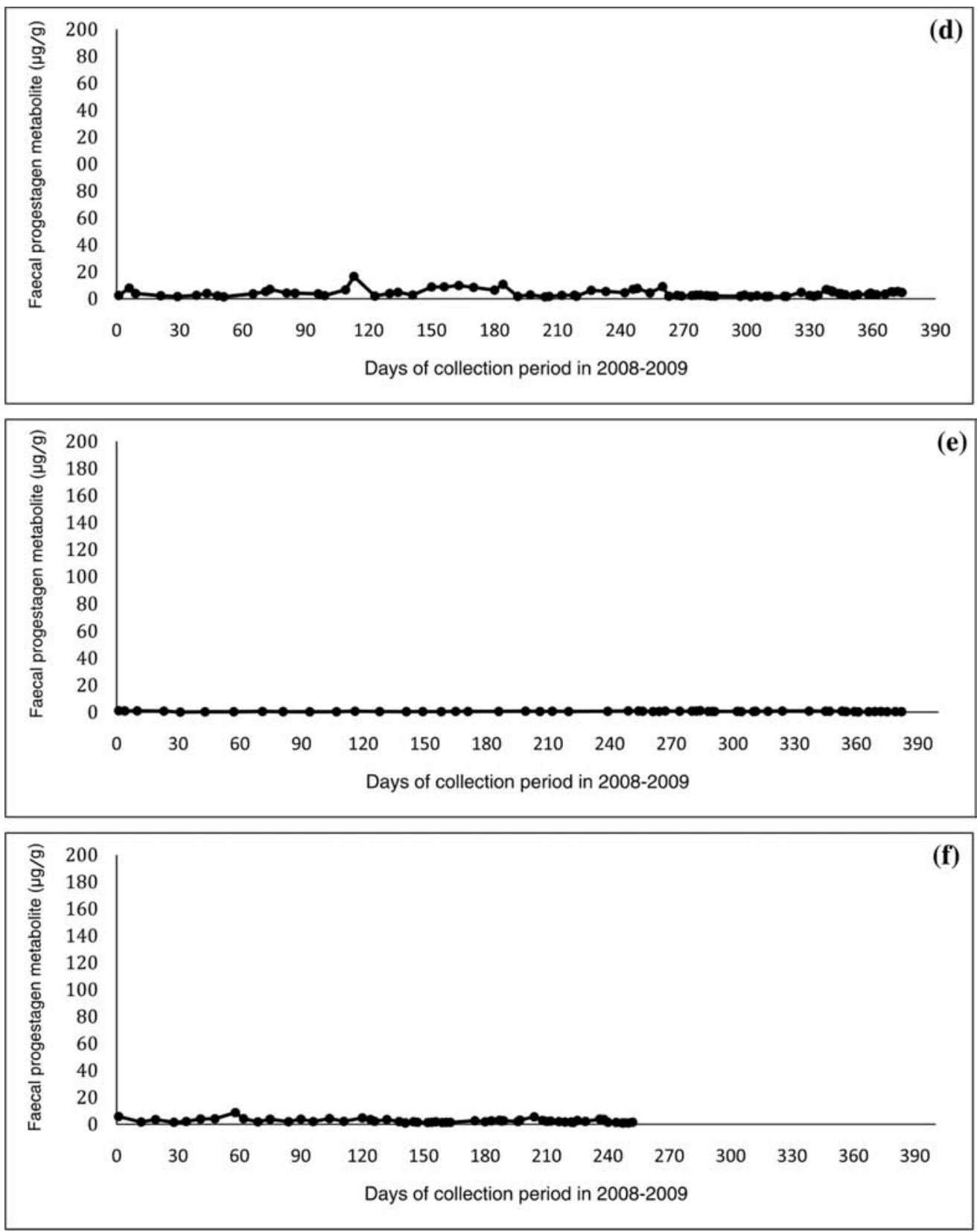

Fig. 2 (Continued).

cantly higher then the post-partum values, the differences were several orders of magnitude lower than the differences to the pregnant phase $(4.05 \pm 2.63 \mu \mathrm{g} / \mathrm{g}$ faeces, $2.54 \pm 1.42 \mu \mathrm{g} / \mathrm{g}$ faeces, $0.58 \pm 0.22 \mu \mathrm{g} / \mathrm{g}$ faeces; Fig. $2 \mathrm{~d}, \mathrm{e}, \mathrm{f})$. In one of the three non-pregnant females (Fig. 2d) attempted mounting behaviour was observed (no observed penetration) during the course of the study.

\section{DISCUSSION}

Knowledge of the reproductive biology of wild animals can provide valuable information for the development of appropriate in situ and ex situ management plans. This paper provides the first description of progestagen metabolite profiles of non-pregnant wild white rhinoceroses ranging freely in their natural habitat as well as individual 
females during the latter stages of pregnancy, parturition and during the postpartum period.

Mean FPM concentrations in all pregnant females were substantially higher during pregnancy than postpartum and non-pregnant status. This technique thus facilitates the detection of pregnancy in wild individuals in a non-invasive way, which can also be useful for surveillance strategies and the detection of foetal death during pregnancy. The mean FPM profiles in wild southern white rhinoceroses found in this study resemble those found in captive white rhinoceros individuals (Schwarzenberger et al. 1998; Patton et al. 1999). The number of samples collected for this study was insufficient to detect ovarian cycling patterns. It would therefore be necessary to conduct a study equivalent to this one, focusing on more regular long-term monitoring of FPM patterns in wild non-pregnant individuals. Such an approach could be subsequently used to compare the aberrant patterns seen in the captive white rhinoceros with patterns present in successfully reproducing free-living individuals (Schwarzenberger et al. 1998; Swaisgood et al. 2006).

In two of the three monitored pregnant females a suggestion of a decline of progestagen metabolite concentration prior to parturition was observed (Fig. 2b,c). In a previous study describing $5 \alpha$ reduced pregnane profiles in captive white rhinoceroses this decline prior to parturition was not seen (Patton et al. 1999). However, another study found a decline in FPM during the last two weeks of pregnancy in the captive black rhinoceros (Schwarzenberger et al. 1993), although this could also be related to the specificity of the antibody used. More detailed endocrine data from white rhinoceroses around parturition are needed to reach a consensus conclusion as to whether a decline of FPM concentrations is, or is not, present in the wild white rhinoceros prior to and/or after parturition.

The data collected 120-140 days following parturition seem to show a consistent postpartum period of reproductive inactivity of at least 120 days in all three females. This observation has been described for white (Schwarzenberger et al. 1999) and Indian (Rietschel 2000) rhinoceroses in captivity as well as black rhinoceroses in the wild (Garnier et al. 2002).

As a potential alternative approach to progestagen measurement, ovarian characteristics and pregnancy could be monitored by measuring faecal oestrogen metabolites. An appropriate assay has to be carefully validated in terms of applicability for the species-specific hormone matrix of interest to ensure reliable hormone quantification (Hodges et al. 2010), and so far, no test system exist for a reliable measurement of oestrogen metabolites in white rhinoceros faeces. If studies like these in wild individuals can be expanded, through more frequent faecal collection and/or the validation of a faecal oestrogen metabolite assay, as demonstrated for the Indian rhinoceros (Stoops et al. 2004), data derived from such studies will provide us with new information on the reproductive physiology of the white rhinoceros, which could help considerably in diagnosing, understanding and solving the current breeding problem seen in captivity. Furthermore, new insights on endocrine patterns through in situ research on the southern white rhinoceros subspecies could help us finding strategies to understand cyclicity and pregnancy patterns and to increase breeding success in the critically endangered northern white rhinoceros subspecies.

\section{ACKNOWLEDGEMENTS}

We wish to thank the Institute for Breeding Rare and Endangered African Mammals (IBREAM) for making this research possible. We are indebted to the following students from the faculty of Veterinary Medicine at Utrecht University for their contribution in collecting faecal samples: Yvette Charbon, Belinda Bitter, Meike Meijers and Julie Swinkels. We are especially thankful to Thomas Litshani, whose exceptional rhinoceros knowledge and tracking skills greatly contributed to the number of samples collected. We are most grateful to the management of the Lapalala Wilderness reserve: Duncan Parker, Mike Gregor, Anton Walker, Roger Collinson and Anthony and Erin Roberts for permission to conduct research in the reserve as well as for their help and support. We also thank John Hanks and Henk Bertschinger for their encouragement and helpful advice, and Stefanie Ganswindt for expert help in laboratory techniques.

\section{REFERENCES}

AHLERS, M.J., GANSWINDT, A., MÜNSCHER, S. \& BERTSCHINGER, H.J. 2012. Fecal 20-oxo-pregnane concentrations in free-ranging African elephants (Loxodonta africana) treated with porcine zona pellucida vaccine. Theriogenology 78: 77-85.

AMIN, R., BRAMER, M. \& EMSLIE, R. 2003. Intelligent data analysis for conservation: Experiments with rhino horn fingerprint identification. KnowledgeBased Systems 16: 329-336. 
AZA 2009. Rhino Research Advisory Group: Five-year Research Master Plan for Rhinoceros. American Zoo and Aquarium Association, San Diego.

BEN-SHAHAR, R. 1987. Grasses and habitat relationships on a sour bushveld nature reserve. Vegetation 72: $45-49$.

BERTSCHINGER, H.J. 1994. Reproduction in black and white rhinos: a review. In: Proceedings of a Symposium on Rhinos as Game Ranch Animals, Onderstepoort, South Africa, 9-10 September 1994, pp. 96-99.

BROWN, J.L., BELLEM, A.C., FOURAKER, M., WILDT, D.E. \& ROTH, T.L. 2001. Comparative analysis of gonadal and adrenal activity in the black and white rhinoceros in North America by noninvasive endocrine monitoring. Zoo Biology 20: 463-486.

CHRISTENSEN, B.W., TROEDSSON, M., LITTLE, R., OLIVA, M. \& PENFOLD, L. 2006. Invasive and non-invasive methods of hormone monitoring in captive wildlife. In: Proceedings of the Fourth Rhino Keepers Workshop 2005, Columbus, Ohio.

COSTA-NETO, E. 2004. Implications and applications of folk zootherapy in the state of Bahia, northeastern Brazil. Sustainable Development 12: 161-174.

EMSLIE, R. 2011. Ceratotherium simum ssp. simum. In: IUCN 2012. IUCN Red List of Threatened Species. Version 2012.2. Online at: http://www.iucnredlist.org (downloaded 28 November 2012).

EMSLIE, R.H., AMIN, R. \& KOCK, R. 2009. Guidelines for the in situ re-introduction and translocation of African and Asian rhinoceros. Occasional Paper of the IUCN Species Survival Commission 39: 16.

EMSLIE, R.H. \& BROOKS, M. 1999. African Rhino: Status Survey and Conservation Action Plan. IUCN/SSC African Rhino Specialist Group, Gland, Switzerland, and Cambridge, U.K.

FERREIRA, S.M., BOTHA, J.M. \& EMMETT, M.C. 2012. Anthropogenic influences on conservation values of white rhinoceros. PLOS ONE 7: e45989.

FIEß, M., HEISTERMANN, M. \& HODGES, J.K. 1999. Patterns of urinary and fecal steroid excretion during the ovarian cycle and pregnancy in the African elephant (Loxodonta africana). General and Comparative Endocrinology 115: 76-89.

FOOSE, T.J. \& WIESE, R.J. 2006. Population management of rhinoceros in captivity. International Zoo Yearbook 40: 174-196.

GARNIER, J., HOLT, W., \& WATSON, P. 2002. Noninvasive assessment of oestrous cycles and evaluation of reproductive seasonality in the female wild black rhinoceros (Diceros bicornis minor). Reproduction 123: 877-889.

HERMES, R., HILDEBRANDT, T.B., BLOTTNER, S., WALZER, C., SILINSKI, S. \& PATTON, M.L. 2005. Reproductive soundness of captive southern and northern white rhinoceroses (Ceratotherium simum simum, C.s. cottoni): Evaluation of male genital tract morphology and semen quality before and after cryopreservation. Theriogenology 63: 219-238.

HERMES, R., HILDEBRANDT, T.B., WALZER, C., GÖRITZ, F., PATTON, M.L., SILINSKI, S., ANDERSON, M.J., REID, C.E., WIBBELT, G., TOMASOVA, K. \& SCHWARZENBERGER, F. 2006. The effect of long non-reproductive periods on the genital health in captive female white rhinoceroses (Ceratotherium simum simum, C. s. cottoni). Theriogenology 65: 1492 1515.

HINDLE, J.E., MOST, E. \& HODGES, J.K. 1992. Measurement of urinary oestrogens and 20 \{alpha\}-dihydroprogesterone during ovarian cycles of black (Diceros bicornis) and white (Ceratotherium simum) rhinoceroses. Journal of Reproduction and Fertility 94: 237-249.

HODGES, K., BROWN, J. \& HEISTERMANN, M. 2010. Endocrine monitoring of reproduction and stress. In: Wild Mammals in Captivity: Principles and Techniques for Zoo Management, (eds) D.G. Kleiman, K.V. Thompson \& C. Kirk Baer, pp. 447-468. University of Chicago Press, Chicago.

KNIGHT, M. 2011. African Rhino Specialist Group report. Pachyderm 49: 6-15.

MILLIKEN, T., EMSLIE, R.H. \& TALUKDAR, B. 2009. African and Asian rhinoceroses - status, conservation and trade. A report from the IUCN species survival commission (IUNC/SSC) African and Asian rhino specialist groups and TRAFFIC to the CITES secretariat. The Hague, November 2009.

LOW, A.B. \& REBELO, T.G. 1996.Vegetation of South Africa, Lesotho and Swaziland. Department of Environmental Affairs and Tourism, Pretoria, South Africa.

OWEN-SMITH, R.N. 1992. Megaherbivores: The Influence of Very Large Body Size on Ecology. Cambridge University Press.

PATTON, M.L., SWAISGOOD, R.R., CZEKALA, N.M., WHITE, A.M., FETTER, G.A. \& MONTAGNE, J.P. 1999. Reproductive cycle length and pregnancy in the southern white rhinoceros (Ceratotherium simum simum) as determined by fecal pregnane analysis and observations of mating behavior. Zoo Biology 18: 111-127.

PINHEIRO, J.C. \& BATES, D.M. 2000. Mixed Effect Models in $S$ and S-plus. Springer Verlag, New York.

RADCLIFFE, R. W., CZEKALA, N.M. \& OSOFSKY, S.A. 1997. Combined serial ultrasonography and fecal progestin analysis for reproductive evaluation of the female white rhinoceros (Ceratotherium simum simum): Preliminary results. Zoo Biology 16: 445-456.

REID, C.E., VERSTEEGE, L., LUDWIG, A. \& HERMES, R. 2012. Analysis of the European captive southern white rhinoceros (Ceratotherium simum simum) population using the International Studbook for the African White Rhinoceros (2001-2004) and integrating reproductive health findings. International Zoo Yearbook 46: 209-220.

RIETSCHEL, W. 2000. Case report and veterinary aspects of breeding the Indian rhino (Rhinoceros unicornis) at Stuttgart Zoo. In: Proceedings of the Third meeting of the European Association of Zoo and Wildlife Veterinarians, Paris, pp. 195-200.

ROOKMAAKER, K. 2001. The alleged population reduction of the southern white rhinoceros (Ceratotherium simum simum) and the succesful recovery. Säugetierkundliche Mitteilungen 45: 55-70.

ROTH, T.L. 2006. A review of the reproductive physiology of rhinoceros species in captivity. International Zoo Yearbook 40: 130-143.

SCHWARZENBERGER, F., FRANCKE, R. \& GOLTENBOTH, R. 1993. Concentrations of fecal immunoreactive progestagen metabolites during the oestrous cycle and pregnancy in the black rhinoceros (Diceros 
bicornis michaeli). Journal of Reproduction and Fertility 98: 285-291.

SCHWARZENBERGER, F., WALZER, C., TOMASOVA, K., VAHALA, J., MEISTER, J. \& GOODROWE, K.L. 1998. Fecal progesterone metabolite analysis for non-invasive monitoring of reproductive function in the white rhinoceros (Ceratotherium simum). Animal Reproduction Science 53: 173-190.

SCHWARZENBERGER, F., WALZER, C., TOMASOVA, K., ZIMA, J., GORITZ, F. \& HERMES, R. 1999. Can the problems associated with the low reproductive rate in captive white rhinoceroses (Ceratotherium simum) be solved within the next 5 years? Erkrankungen der Zootiere 39: 283-289.

SZDZUY, K., DEHNHARD, M., STRAUSS, K., EULENBERGER, K. \& HOFER, H. 2006. Behavioural and endocrinological parameters of female African and Asian elephants. International Zoo Yearbook 40: 41-50.
STEELE, V. 2002. Blood collection. In: Proceedings of the [second] Rhino Keepers' Workshop, pp. 43-44.

STOOPS, M.A., PAIRAN, R.D. \& ROTH, T.L. 2004. Follicular, endocrine and behavioural dynamics of the Indian rhinoceros (Rhinoceros unicornis) oestrous cycle. Reproduction 128: 843-856.

SWAISGOOD, R.R., DICKMAN, D.M. \& WHITE, A.M. 2006. A captive population in crisis: testing hypotheses for reproductive failure in captive-born southern white rhinoceros females. Biological Conservation 129: 468-476.

WALKER, C.H. 1994. Black rhino on private land - the experience of Lapalala Wilderness, South Africa. Pachyderm 18: 44-45.

WITTEMYER, G., GANSWINDT, A. \& HODGES, K. 2007. The impact of ecological variability on the reproductive endocrinology of wild female African elephants. Hormones and Behavior 51: 346-354.

Responsible Editor: J.H. van Wyk 